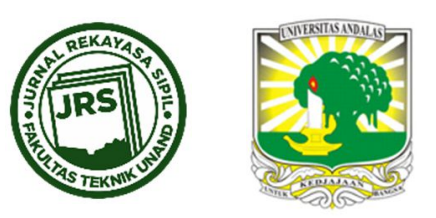

\title{
PENGARUH PENUTUPAN PERLINTASAN SEBIDANG KERETA API DI JALAN H.O.S. COKROAMINOTO, YOGYAKARTA
}

\author{
PRIMA JUANITA ROMADHONA ${ }^{{ }^{*}}$, SHAFIRA ARTISTIKA ${ }^{1}$ \\ ${ }^{1}$ Jurusan Teknik Sipil,Fakultas Teknik Sipil dan Perencanaan, Universitas Islam Indonesia, Yogyakarta \\ author: هprima_dhona@uii.ac.id
}

Naskah diterima : 20 Desember 2019. Disetujui: 14 Juli 2020

\begin{abstract}
ABSTRAK
Maraknya kecelakaan transportasi khususnya pada perlintasan sebidang kereta api membuat pemerintah berupaya untuk menutup perlintasan sebidang. Penelitian ini bertujuan untuk mengetahui kinerja ruas sekitar perlintasan sebidang kereta api Jalan H.O.S. Cokroaminoto Yogyakarta kondisi eksisting, penutupan perlintasan, dan penutupan perlintasan dengan flyover. Hasil kinerja tersebut kemudian digunakan untuk mendapatkan tingkat pelayanan ruas jalan. Tujuan selanjutnya memberikan permodelan lalu lintas akibat penutupan perlintasan kereta api pada perlintasan tersebut. Penelitian ini membutuhkan survei lapangan berupa volume lalu lintas, kecepatan kendaraan, driving behavior, waktu siklus, dan waktu kedatangan kereta api yang melintas. Analisis kinerja ruas jalan menggunakan Manual Kapasitas Jalan Indonesia 1997 untuk mengetahui nilai derajat kejenuhan, dan untuk mengetahui nilai kecepatan kendaraan menggunakan aplikasi permodelan VISSIM. Dari hasil tersebut kemudian dapat diketahui tingkat pelayanan ruas jalan yang mengacu pada Peraturan Menteri Perhubungan nomor PM 96 Tahun 2015. Hasil penelitian menunjukkan pada kondisi penutupan perlintasan, nilai derajat kejenuhan pada semua ruas jalan mengalami penurunan, yang menunjukkan peningkatan kinerja ruas jalan, kecuali di Jalan Pembela Tanah Air pada simpang 3 Selatan perlintasan, karena terjadi pembebanan volume pada ruas tersebut. Kecepatan kendaraan berbanding lurus dengan derajat kejenuhan, hanya di Jalan Pembela Tanah Air yang mengalami penurunan kecepatan. Pada kondisi penutupan perlintasan dengan flyover, semua ruas mengalami penurunan derajat kejenuhan yang berarti peningkatan kinerja ruas jalan dengan pelebaran jalan pada Jalan Pembela Tanah Air. Sedangkan untuk kecepatan, hanya ruas yang berada tepat di sebelah Utara perlintasan saja yang mengalami penurunan dikarenakan kondisi menanjak pada flyover.
\end{abstract}

Kata kunci : Penutupan perlintasan kereta api, VISSIM, Jalan H.O.S. Cokroaminoto Yogyakarta

\section{PENDAHULUAN}

Keselamatan adalah salah satu kunci utama dalam penyediaan jasa transportasi. Masyarakat sebagai pengguna jalan wajib mematuhi peraturan - peraturan yang ada agar menciptakan keselamatan dalam perjalanan kereta api, seperti dalam Peraturan Pemerintah Nomor 72 
Tahun 2009 tentang Lalu Lintas dan Kereta Api Pasal 110 (Republik Indonesia, 2009), yaitu tentang pemakai jalan wajib mendahulukan perjalanan kereta api.

Meski telah jelas tertera dalam Peraturan Pemerintah, masih banyak pengendara lain yang nekat menerobos palang pintu padahal palang sudah perlahan turun, sehingga kecelakaanpun tak dapat dihindari.

Perlintasan yang terletak di Jalan H.O.S. Cokroaminoto, Yogyakarta menjadi salah satu target penutupan oleh Kementrian Perhubungan sebagai salah satu upaya untuk mengurangi kecelakaan kereta api. Saat melakukan survei lokasi perlintasan, terlihat masih banyak pengendara sepeda motor yang nekat menerobos, padahal palang pintu sudah turun penuh. Hal ini dipicu karena palang perlintasan tidak dibuat double untuk masing-masing arah sehingga banyak pengguna jalan yang bisa menerobos. Berdasarkan Permenhub Nomor 36 Tahun 2011 (Menteri Perhubungan Republik Indonesia, 2011), kriteria perlintasan yang berpotensi untuk ditutup adalah perlintasan sebidang yang sudah memiliki alternatif berupa flyover, underpass, frontage road, jalan kolektor, perlintasan sebidang yang rawan kecelakaan (ditutup pada saat pasca terjadinya kecelakaan di lokasi). Kondisi perlintasan di Jalan H.O.S. Cokroaminoto akan mudah memicu terjadinya kecelakaan antar pengguna jalan, sehingga pada perlintasan tersebut memungkinkan untuk ditutup.

Salah satu alternatif agar lalu lintas kendaraan lain tetap berjalan adalah dengan pembangunan flyover. Hal ini terdapat dalam Undang - Undang Nomor 23 tahun 2007 tentang Perkeretaapian (Republik Indonesia, 2007), yaitu setiap perpotongan antara jalur kereta api dengan jalan raya harus dibuat tidak sebidang. Jalan raya naik dibuat flyover atau turun dibuat terowongan atau underpass.

Penelitian ini bertujuan mengetahui kinerja ruas sekitar perlintasan sebidang kereta api Jalan H.O.S. Cokroaminoto Yogyakarta kondisi eksisting, penutupan perlintasan, dan penutupan perlintasan dengan flyover.

Muttaqin, Sumarsono, and Dewi (2014) menganalisis adanya pengoperasian palang pintu kereta api di Purwosari terhadap konsumsi bahan bakar. Konsumsi BBM rata-rata di Jalan Slamet Riyadi sebesar $74.891 \mathrm{cc} / \mathrm{smp}$ hal ini disebabkan oleh lamanya tundaan yang dialami oleh kendaraan yang melewati serta perilaku pengguna kendaraan bermotor yang tidak beraturan pada saat pembukaan pintu perlintasan kereta api.

Muthmainnah (2015) menganalisis kerugian konsumsi bahan bakar akibat penutupan perlintasan kereta api di Lempuyangan. Kerugian konsumsi bahan bakar pada lokasi penelitian dalam sehari adalah sebesar Rp 2.438.908,- berdasarkan metode LAPI-ITB dan untuk metode ATIS India kerugiannya hanya sebesar Rp 1.311.282,-. Alternatif paling optimal adalah dengan pengalihan arus atau mengkonversi kendaraan yang lebih kecil ke dalam kendaraan yang lebih besar (angkutan umum) dengan tanpa mengurangi arus yang terjadi yang mana dapat mengurangi biaya konsumsi BBM hingga 45\% dari kondisi eksisting.

Penelitian Mulyono, Slamet, and Suwardi (2006) menganalisis besar kerugian adanya antrean dan tundaan akibat perlintasan sebidang di Ledok Sari, Surakarta. Besar kerugian yang ditanggung para pengguna jalan bila waktu dinilai dengan uang dalam 1 tahun akibat lintasan kereta api sebesar Rp 2.865.250.000,-/tahun, kerugian bahan bakar minyak akibat adanya lintasasan kereta api sebesar Rp 40.980.375,-/tahun sehingga sudah saatnya pada perlintasan dibangun flyover. 
Sitorus and Surbakti (2013) melakukan penelitian tentang kinerja ruas jalan pada perlintasan sebidang di Jalan Sisingamangaraja, Medan dengan hasil analisis berupa biaya perjalanan akibat penurunan kecepatan pada kedua jalur lalu lintas Rp 156.340.304,--/tahun. Biaya tundaan akibat penutupan pintu perlintasan sebesar Rp 185.829.649,-/tahun. Sehingga biaya tundaan total sebesar Rp 342.169.953,-/tahun.

Hartono (2016) meneliti kinerja ruas jalan akibat perlintasan sebidang kereta api di Jalan Slamet Riyadi, Jalan Kartini, Jalan Tentara Pelajar dan Jalan Kesambi di Kota Cirebon beserta alternatif solusinya. Kinerja ruas jalan di Jalan Slamet Riyadi (V/C) rasio sebesar 0,32, Jalan R.A Kartini sebesar 0,77, Jalan Tentara Pelajar sebesar 0,57 dan Jalan Kesambi Raya sebesar 0,38. Panjang antrean kendaraan pada perlintasan sebidang dan jalan di Kota Cirebon akibat penutupan perlintasan sebidang di Jalan Kartini ke arah Barat yang terpanjang pada saat peak siang yaitu pukul 12.12 WIB sebanyak 135 kendaraan atau mencapai $125 \mathrm{~m}$, sedangkan ke arah Timur pada peak siang yaitu pukul 12.37 WIB sebanyak 327 kendaraan atau $195 \mathrm{~m}$. Pemecahan masalah jangka pendek perlu melihat kondisi jalan, menambahkan rambu, perbaikan trotoar dan marka yang diperlukan, sedangkan untuk jangka panjang perlu dibuat persilangan tidak sebidang, seperti flyover atau underpass.

Hasil penelitian Putra, Mahmudah, and Setiawan (2013) mengevaluasi dan menganalisis kelengkapan infrastruktur, geometrik, tundaan kendaraan, antrian kendaraan, volume kendaraan, dan kondisi struktur permukaan perkerasan jalan di Jalan Sorowajan Baru, Banguntapan, Bantul, Daerah Istimewa Yogyakarta, pada JPL $348 \mathrm{~km} 163+220$. Hasil penelitiannya: (1) Perlintasan dikatakan cukup layak dalam hal tingkat keselamatan bagi pengendara atau pengguna jalan yang melintas pada perlintasan sebidang tersebut; (2) Kelengkapan infrastruktur pada perlintasan ini belum memenuhi standar teknis yang berlaku; (3) Geometrik jalan raya memiliki sudut perpotongan $83^{\circ}$, jari-jari tikungan pertama 9,78 $\mathrm{m}$ dengan kecepatan eksisting rata-rata $17,5 \mathrm{~km} / \mathrm{jam}$ dan tikungan kedua 20,44 $\mathrm{m}$ dengan kecepatan eksisting ratarata $25 \mathrm{~km} / \mathrm{jam}$ yang memenuhi persyaratan; (4) Arus lalu lintas pada hari Sabtu, 25 Maret 2017 didapatkan hasil total sebesar 2246,4 $\mathrm{kend} / \mathrm{jam}$ atau $598,08 \mathrm{skr} / \mathrm{jam}$ dari arah Selatan, sedangkan dari arah Utara didapatkan total sebesar 3230,4 kend/jam atau 877,92 skr/jam. hari Senin, 27 Maret 2017 didapatkan hasil total sebesar $2568 \mathrm{kend} / \mathrm{jam}$ atau $579,84 \mathrm{skr} / \mathrm{jam}$ dari arah selatan, sedangkan dari utara didapatkan total sebesar 2985,6 kend/jam atau $798 \mathrm{skr} / \mathrm{jam}$; (5) Nilai indeks kondisi struktur perkerasan (PCI) rata-rata pada Jalan Sorowajan Baru adalah 69,28\% yang termasuk dalam kategori baik.

Penelitian oleh Widodo (2007) melakukan kajian penutupan perlintasan sebidang di Jalan KH. Mas Mansyur dan Jalan Abdul Syafi'ie Provinsi DKI Jakarta, yang bertujuan untuk mendapatkan biaya operasional kendaraan sebelum dan sesudah penutupan perlintasan sebidang. Hasilnya terjadi kenaikan biaya operasional kendaraan pada setiap ruas jalannya.

Hasil penelitian Yusyadiputra, Hermawanto, Pudjianto, and Yulipriyono (2014) tentang pengaruh penutupan perlintasan kereta api terhadap kinerja lalu lintas jalan raya di segmen Jalan Kaligawe, Semarang dan Jalan Kaliwungu, Kendal, dengan nilai DS pada Jalan Kaligawe sebesar 0,4 dimana jalan tersebut tidak mampu menampung lalu lintas, dan nilai DS pada Jalan Kaliwungu sebesar 0,75 dimana jalan tersebut tidak mampu menampung lalu lintas saat terjadi penutupan palang pintu kereta api pada perlintasan sebidang tersebut.

Winnetou and Munawar (2015) meneleti kevalidan software VISSIM dalam menganalisis kinerja ruas jalan jika dibandingkan dengan analisis kinerja ruas jalan dengan metode MKJI 1997. Metode yang digunakan yaitu survei di lapangan menghasilkan volume arus lalu lintas, kecepatan tiap jenis kendaraan dan geometrik jalan. Kemudian menganalisis data dengan 
mencari nilai kecepatan kendaraan menggunakan MKJI 1997, software VISSIM dan kecepatan di lapangan. Hasilnya, proses kalibrasi sangat berpengaruh pada VISSIM, kalibrasi dilakukan trial sebanyak 9 kali. Didapat trial ke-7 karena volume kendaraannya sudah memenuhi proses validasi. Hal ini menunjukkan bahwa VISSIM dapat memberikan hasil yang berbeda yaitu dengan melakukan perubahan pada driving behaviour.

Ramanti (2017) melakukan analisis volume lalu lintas, panjang antrean, dan tundaan akibat penutupan perlintasan sebidang di Timoho. Didapatkan volume lalu lintas akibat penutupan perlintasan sebidang dengan rentang waktu tertentu paling besar 3932 kendaraan/hari dengan rata-rata tundaan sebesar 75 detik, dan panjang antrean terbesar dari arah Selatan sebesar $210 \mathrm{~m}$, dari arah Utara sebesar $110 \mathrm{~m}$.

Dalam jurnal Purnama and Indarto (2017) membahas tentang mendesain flyover untuk melewati kereta api pada perpotongan jalan Slamet Riyadi dan perlintasan kereta api Purwosari. Metode yang digunakan adalah analisis geometrik flyover dan perhitungan konstruksi metode Load and Resistance Factor Design.

\section{PEMODELAN LALU LINTAS}

\section{1. pemilihan rute}

Menurut Tamin (2000), terdapat tiga hipotesis yang dapat digunakan dalam memilih rute adalah sebagai berikut.

1. Pembebanan all or nothing yaitu pemakai jalan mengetahui rute terpendek yang meminimumkan waktu tempuh dan semuanya menggunakan rute tersebut, tidak ada yang menggunakan rute lain.

2. Pembebanan banyak ruas mengasumsikan pemakai jalan tidak mengetahui informasi yang tepat mengenai rute tercepat. Pengendara memilih rute yang dikiranya adalah rute tercepat, tetapi persepsi yang berbeda untuk setiap pemakai jalan mengakibatkan bermacam-macam rute akan dipilih antara dua zona tertentu.

3. Pembebanan berpeluang mengasumsikan pemakai jalan menggunakan beberapa faktor rute dalam pemilihan rutenya dengan meminimumkan hambatan transportasi contohnya faktor yang tidak dapat dikuantifikasi seperti rute yang aman dan rute yang panoramanya indah. Pengendara memperhatikan faktor lain selain jarak, waktu tempuh dan biaya yang minimum, misalnya rute yang telah dikenal atau yang dianggap aman.

\subsection{Geometri perlintasan tak sebidang (flyover)}

Persyaratan mengenai ruang yang diijinkan untuk perlintasan atau perpotongan diatur dalam Peraturan Menteri Perhubungan Nomor 36 Tahun 2011 tentang Perpotongan dan/atau Persinggungan Antara Jalur Kereta Api dengan Bangunan Lain (Menteri Perhubungan Republik Indonesia, 2011). Perpotongan di atas jalur kereta api dengan bangunan harus memenuhi ketentuan sebagai berikut.

1. Ruang tinggi minimal $6,2 \mathrm{~m}$ dari kepala rel.

2. Ruang sisi kiri dan sisi kanan dari jalur kereta api minimal $10 \mathrm{~m}$ dihitung dari as rel terluar.

3. Pondasi bangunan ditanam minimal 1,5 $\mathrm{m}$ dibawah permukaan tanah dengan jarak minimal $10 \mathrm{~m}$.

4. Dipasang alat pengaman. 


\section{3. derajat kejenuhan (DS)}

Direktorat Jenderal Bina Marga (1997), menyebutkan derajat kejenuhan (DS) digunakan sebagai parameter utama dalam menentukan kinerja suatu ruas jalan. derajat kejenuhan (DS) adalah rasio arus terhadap kapasitas.

Kinerja ruas jalan yang baik memiliki nilai DS kurang dari 0,75. Nilai DS dapat ditentukan menggunakan persamaan 1 berikut.

$$
\mathrm{DS}=\frac{Q}{C}
$$

dengan:

DS = Derajat kejenuhan,

$\mathrm{Q} \quad=$ Arus total ( $\mathrm{smp} / \mathrm{jam})$, dan

$\mathrm{C} \quad=$ Kapasitas (smp/jam).

\section{4. tingkat pelayanan (level of service)}

Menteri Perhubungan Republik Indonesia (2015), menetapkan tingkat pelayanan pada ruas jalan yang dapat dilihat pada tabel 1 .

Tabel 1. Indeks Tingkat Pelayanan pada Ruas Jalan

\begin{tabular}{cl}
$\begin{array}{c}\text { Tingkat } \\
\begin{array}{c}\text { Pelayana } \\
\text { n }\end{array}\end{array}$ & \multicolumn{1}{c}{ Karakteristik Operasi Terkait } \\
\hline $\mathrm{A}$ & $\begin{array}{l}\text { 1. Arus bebas, volume lalu lintas rendah } \\
\text { 2. Kecepatan } \bullet 80 \mathrm{~km} / \mathrm{jam}\end{array}$ \\
\hline $\mathrm{B}$ & $\begin{array}{l}\text { 1. Arus stabil, volume lalu lintas sedang } \\
\text { 2. Kecepatan } \bullet 70 \mathrm{~km} / \mathrm{jam}\end{array}$ \\
\hline $\mathrm{C}$ & $\begin{array}{l}\text { 1. Arus stabil, volume lalu lintas lebih tinggi } \\
\text { 2. Kecepatan } \bullet 60 \mathrm{~km} / \mathrm{jam}\end{array}$ \\
\hline $\mathrm{D}$ & $\begin{array}{l}\text { 1. Arus mendekati tidak stabil, volume lalu lintas tinggi } \\
\text { 2. Kecepatan } \bullet 50 \mathrm{~km} / \mathrm{jam}\end{array}$ \\
\hline $\mathrm{E}$ & $\begin{array}{l}\text { 1. Arus mendekati tidak stabil, volume lalu lintas mendekati kapasitas jalan } \\
\text { 2. Kecepatan } \bullet 30 \mathrm{~km} / \mathrm{jam} \text { pada jalan antar kota, dan } \bullet 10 \mathrm{~km} / \mathrm{jam} \text { pada jalan } \\
\text { perkotaan }\end{array}$ \\
\hline $\mathrm{F}$ & $\begin{array}{l}\text { 1. Arus tertahan, terjadi antrean kendaraan yang panjang, } \\
\text { 2. Kecepatan }<30 \mathrm{~km} / \mathrm{jam}\end{array}$ \\
\hline
\end{tabular}

\section{5. program vissim}

VISSIM dikembangkan oleh Planung Transportasi Verkehr AG di Karlsruhe, Jerman. VISSIM berasal dari Jerman yang mempunyai nama "Verkehr Städten - SIMulationsmodell" yang artinya model simulasi lalu lintas perkotaan (AG, 2016).

Validasi pada VISSIM menggunakan rumus statistik Geoffrey E. Havers (GEH). Rumus uji statistik $G E H$ dapat dilihat pada persamaan 2. Rumus $G E H$ memiliki ketentuan khusus bagi suatu nilai error yang dapat dilihat pada tabel 2.

$$
G E H=\sqrt{\frac{(q \text { simulated }-q \text { observed })^{2}}{0,5 \times(q \text { simulated }+q \text { observed })}}
$$

dengan : 
$\mathrm{q}_{\text {simulated }}=$ data volume lalu lintas (kendaraan $/ \mathrm{jam}$ ) hasil VISSIM

qobserved = data volume lalu lintas (kendaraan/jam) hasil pengamatan

Tabel 2. Pedoman Statistik GEH

\begin{tabular}{ll}
\hline Nilai $G E H$ & Keterangan \\
\hline$G E H<5$ & Diterima \\
\hline $5 \cdot G E H \cdot 10$ & $\begin{array}{l}\text { Peringatan: kemungkinan model } \text { error } \text { atau data } \\
\text { buruk }\end{array}$ \\
\hline$G E H>10$ & Ditolak \\
\hline
\end{tabular}

\section{METODOLOGI PENELITIAN}

Penelitian ini membutuhkan data primer melalui survei lapangan berupa volume lalu lintas, kecepatan kendaraan, driving behavior, waktu siklus, dan waktu kedatangan kereta api yang melintas dan data sekunder berupa peta lokasi dari google earth untuk permodelan pada VISSIM. Data - data tersebut dianalisis dengan pembagian 3 model yaitu model eksisting, model penutupan perlintasan dan model penutupan perlintasan dengan flyover.

Mengacu teori all or nothing, pada kondisi pengalihan rute, kendaraan dari segmen 1 dipindah ke Jalan Kyai Mojo. Kendaraan dari segmen 1 dan Jalan Wiratama yang akan menuju area sekitar Selatan perlintasan dialihkan menuju Jalan Kyai Mojo, belok ke Jalan Tentara Rakyat Mataram, keluar dari simpang menuju bundaran dan melewati perlintasan tak sebidang Jalan Tentara Rakyat Mataram menuju Jalan Pembela Tanah Air. Kendaraan dari segmen 4 dipindah ke Jalan Jlagan Lor. Kendaraan dari segmen 4 dan segmen 5 yang akan menuju area sekitar Utara perlintasan dialihkan menuju perlintasan tak sebidang Jalan Tentara Rakyat Mataram, pada simpang 3 Jalan Tentara Rakyat Mataram-Jalan Kyai Mojo belok ke Barat ke Jalan Kyai Mojo belok ke Selatan menuju Jalan H.O.S. Cokroaminoto. Denah pengalihan rute kondisi penutupan perlintasan dapat dilihat pada gambar 1 .

Pada permodelan kondisi penutupan perlintasan dengan flyover, terdapat perubahan geometri ruas jalan. Daerah bawah flyover arah Utara ke Selatan maupun sebaliknya mengalami pelebaran jalan masing - masing 3 meter. Untuk lebar jalan flyover sendiri merupakan lebar ruas jalan H.O.S. Cokroaminoto kondisi eksisting. Lebar Jalan Pembela Tanah Air (S4) kondisi eksisting masing - masing jalur sebesar 4,1 m dan 4,5 m, mengalami pelebaran jalan masing - masing jalur 6,5 m.

Analisis kinerja ruas jalan menggunakan Manual Kapasitas Jalan Indonesia 1997 (MKJI 1997) untuk mengetahui nilai derajat kejenuhan, untuk mengetahui nilai kecepatan kendaraan menggunakan aplikasi permodelan VISSIM. Dari hasil tersebut kemudia dapat diketahui tingkat pelayanan ruas jalan yang mengacu pada Menteri Perhubungan Republik Indonesia (2015). 


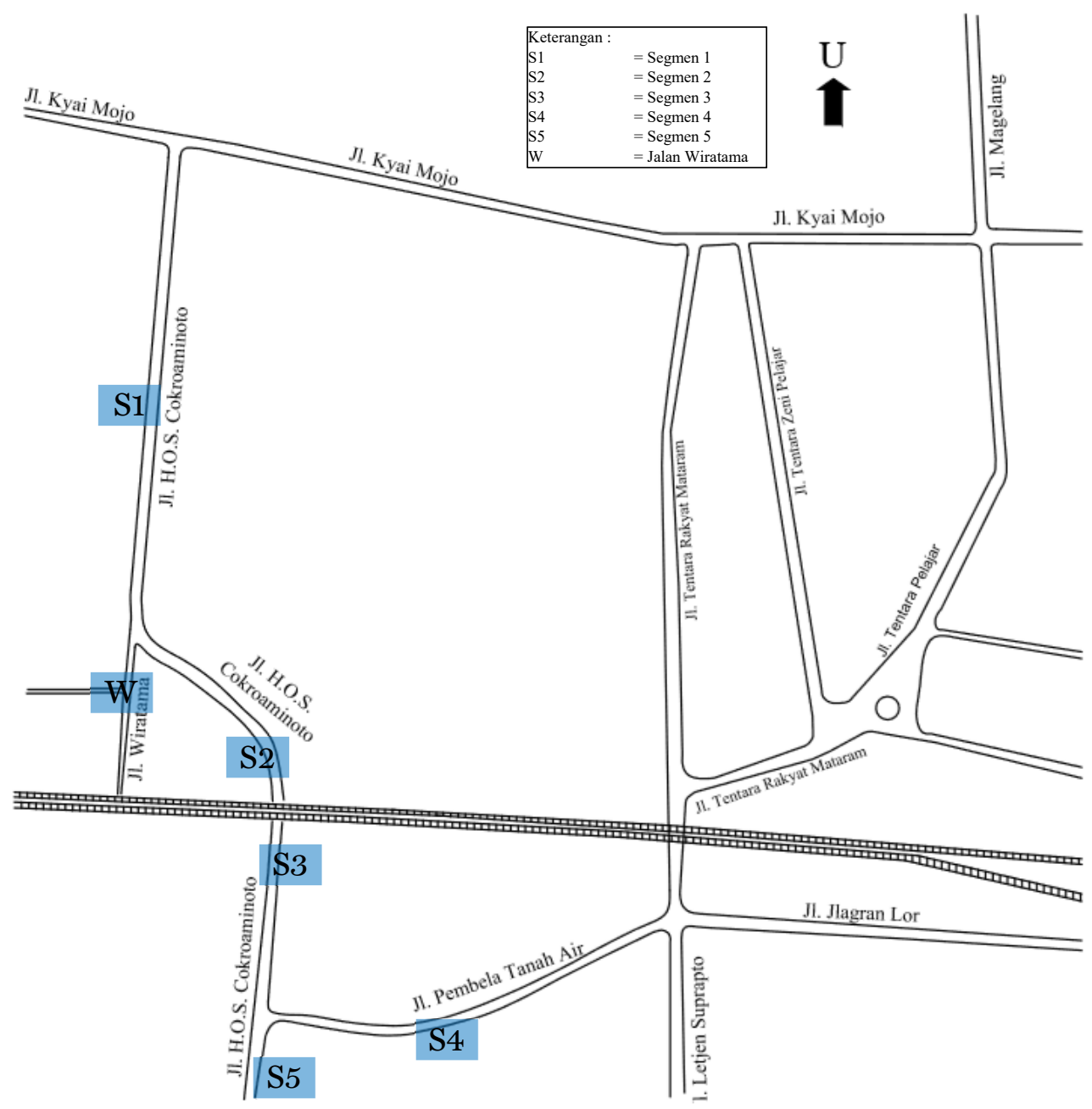

Gambar 1. Denah Pengalihan Arus Kondisi Penutupan Perlintasan

\section{HASIL DAN PEMBAHASAN}

Jam puncak tertinggi terjadi pada Rabu, 28 November 2018 pukul 16.00-17.00 dengan volume sebesar 13471 kendaraan/jam yang dapat dilihat pada gambar 2 . 


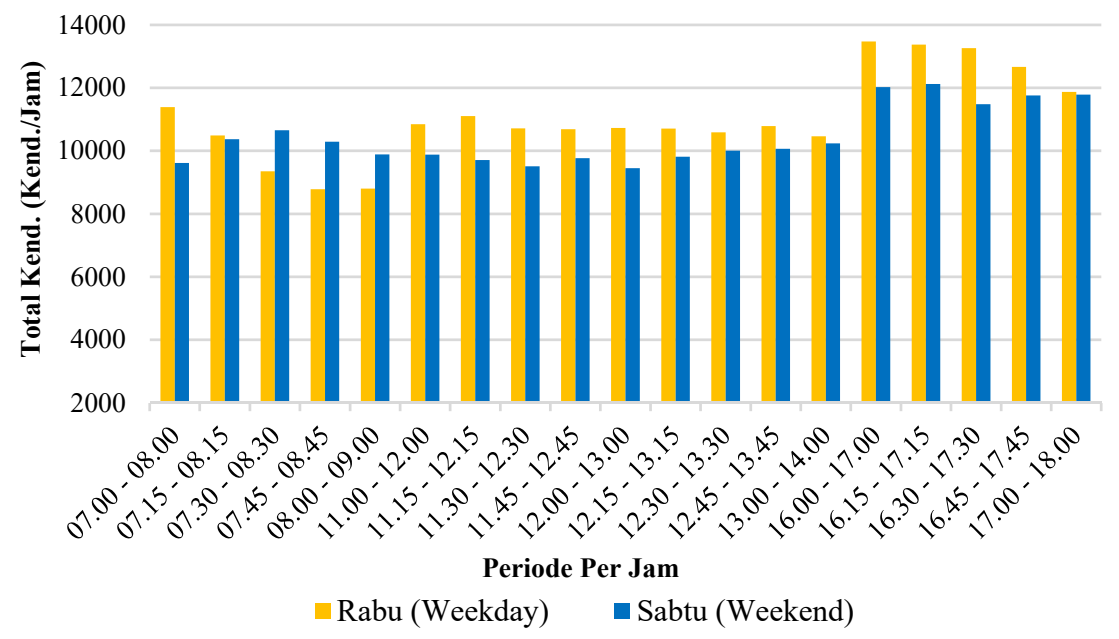

Gambar 2. Data Volume Lalu Lintas Weekdaydan Weekend

Distribusi pergerakan arus lalu lintas per arah pada periode jam puncak area Utara dan Selatan Perlintasan dapat dilihat pada gambar 3. 


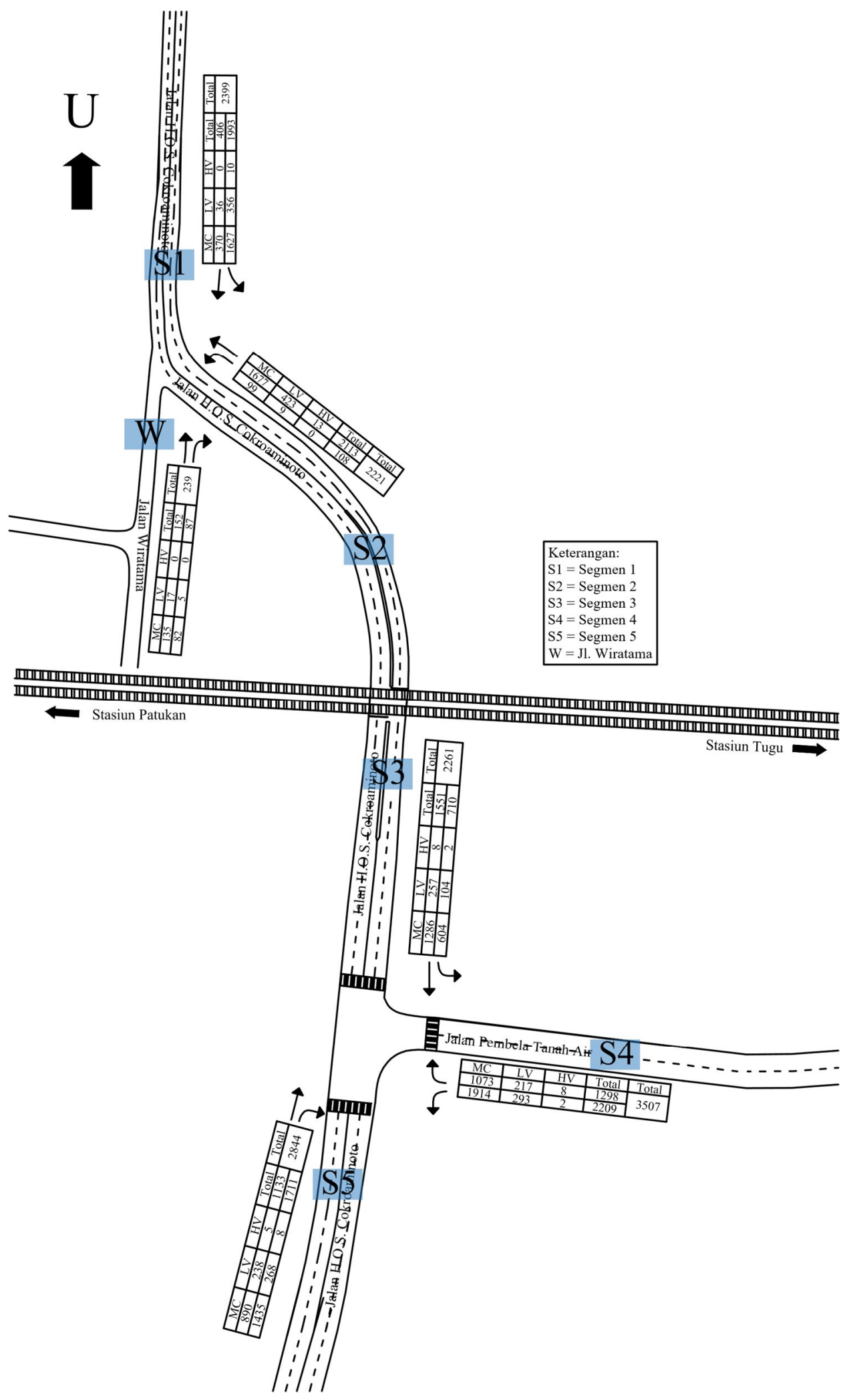

Gambar 3. Distribusi Volume Kendaraan pada Ruas Jalan H.O.S. Cokroaminoto Kondisi Eksisting 
Langkah berikutnya adalah perhitungan nilai derajat kejenuhan (DS) dengan acuan MKJI 1997. Perbedaan nilai derajat kejenuhan (DS) antara kondisi eksisting, penutupan perlintasan, dan penutupan perlintasan dengan flyover dapat dilihat pada tabel 3 . Perbandingan nilai DS juga dapat dilihat dalam bentuk grafik yang dapat dilihat pada gambar 4 .

Tabel 3. Perbandingan Nilai DS

\begin{tabular}{llllll}
\hline \multirow{2}{*}{ Ruas } & \multicolumn{5}{c}{ Derajat Jenuh (DS) } \\
& Eksistin & \multicolumn{2}{c}{ Penutupan } & \multicolumn{2}{c}{ Flyover } \\
& g & Hasil & Ket. (\%) & Hasil & Ket. (\%) \\
\hline Segmen 1 & 0,365 & 0,024 & $-93,321$ & 0,365 & 0 \\
\hline Segmen 2 & 0,308 & 0,007 & $-97,75$ & 0,311 & 0,887 \\
\hline Segmen 3 & 0,35 & 0,015 & $-95,645$ & 0,344 & $-1,674$ \\
\hline Segmen 4 & 0,769 & 1,009 & 31,207 & 0,457 & 40,54 \\
\hline Segmen 5 & 0,495 & 0,495 & $-7,743$ & 0,495 & 0 \\
\hline
\end{tabular}

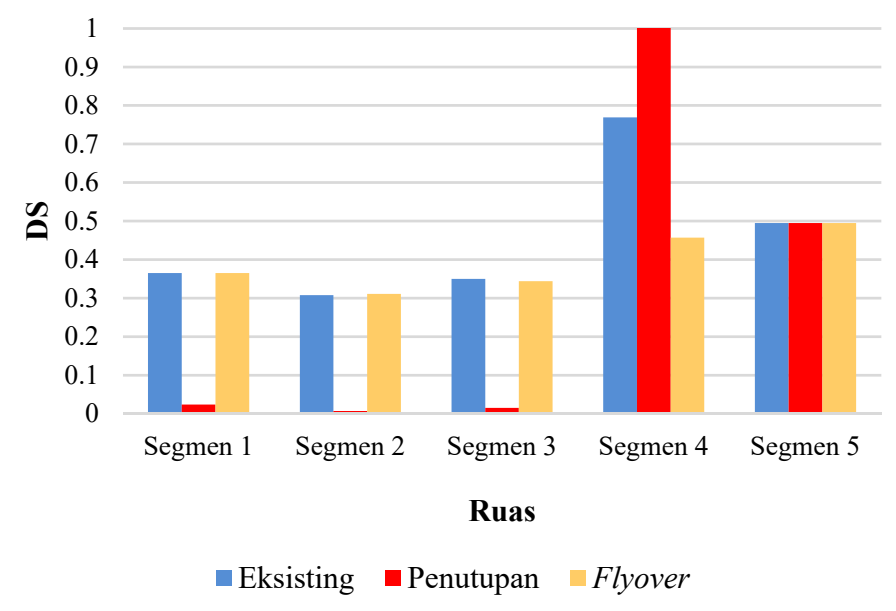

Gambar 4. Grafik Perbandingan Nilai DS

Pada permodelan penutupan perlintasan didapatkan penurunan nilai derajat kejenuhan yang berarti kenaikan kinerja sebesar $93,321 \%$ pada ruas segmen $1,97,75 \%$ pada ruas segmen $2,95,645 \%$ pada ruas segmen 3 , dan $7,743 \%$ pada ruas segmen 5 . Sedangkan, ruas segmen 4 mengalami kenaikan nilai derajat kejenuhan yang berarti penurunan kinerja sebesar $31,207 \%$ karena mengalami pembebanan volume kendaraan dari pengalihan segmen 1, segmen 2, dan dari Jalan Wiratama yang akan menuju ke area Selatan perlintasan sebidang.

Pada permodelan penutupan perlintasan dengan flyover didapatkan penurunan nilai derajat kejenuhan yang berarti kenaikan kinerja sebesar 1,674\% karena belum ada penambahan kendaraan dari bawah flyover area Selatan perlintasan, dan pada ruas segmen 4 mengalami kenaikan yang cukup signifikan yaitu sebesar 40,54\% karena pelebaran jalan. Ruas segmen 2 mengalami kenaikan nilai derajat kejenuhan yang berarti penurunan kinerja sebesar $0,887 \%$ karena telah terjadi penambahan kendaraan dari bawah flyover area Utara perlintasan. Sedangkan ruas segmen 1 dan segmen 5 tidak mengalami perubahan nilai derajat kejenuhan karena volume kendaraan yang melewati ruas tersebut sama dan tidak mengalami perubahan geometri. 
Setelah dilakukan permodelan pada VISSIM didapat hasil validasi tiap ruas dapat dilihat pada tabel 4 berikut.

Tabel 4. Validasi Volume Kendaraan

\begin{tabular}{lllll}
\hline Ruas & $\begin{array}{l}\text { Vol. } \\
\text { Eksisting } \\
\text { (Kend./Jam) }\end{array}$ & $\begin{array}{l}\text { Vol. VISSIM } \\
\text { (Kend./Jam }\end{array}$ & GEH(\%) & $\begin{array}{l}\text { Keteranga } \\
\mathbf{n}\end{array}$ \\
\hline Segmen 1 & 2399 & 2307 & 1,897 & Diterima \\
\hline Segmen 2 & 239 & 238 & 0,065 & Diterima \\
\hline Segmen 3 & 2221 & 2017 & 4,432 & Diterima \\
\hline Segmen 4 & 2261 & 2088 & 3,71 & Diterima \\
\hline Segmen 5 & 3507 & 3285 & 3,81 & Diterima \\
\hline
\end{tabular}

Dari permodelan juga didapatkan hasil kecepatan kendaraan, dan kemudian dari hasil kecepatan tersebut dapat digunakan untuk menentukan tingkat pelayanan ruas Jalan H.O.S. Cokroaminoto pada kondisi eksisting, penutupan perlintasan, dan penutupan perlintasan dengan flyover yang dapat dilihat pada tabel 5 . Perbandingan nilai kecepatan juga dapat dilihat dalam bentuk grafik yang dapat dilihat pada gambar 5 .

Tabel 5. Perbandingan Nilai Kecepatan Kendaraan dan Tingkat Pelayanan

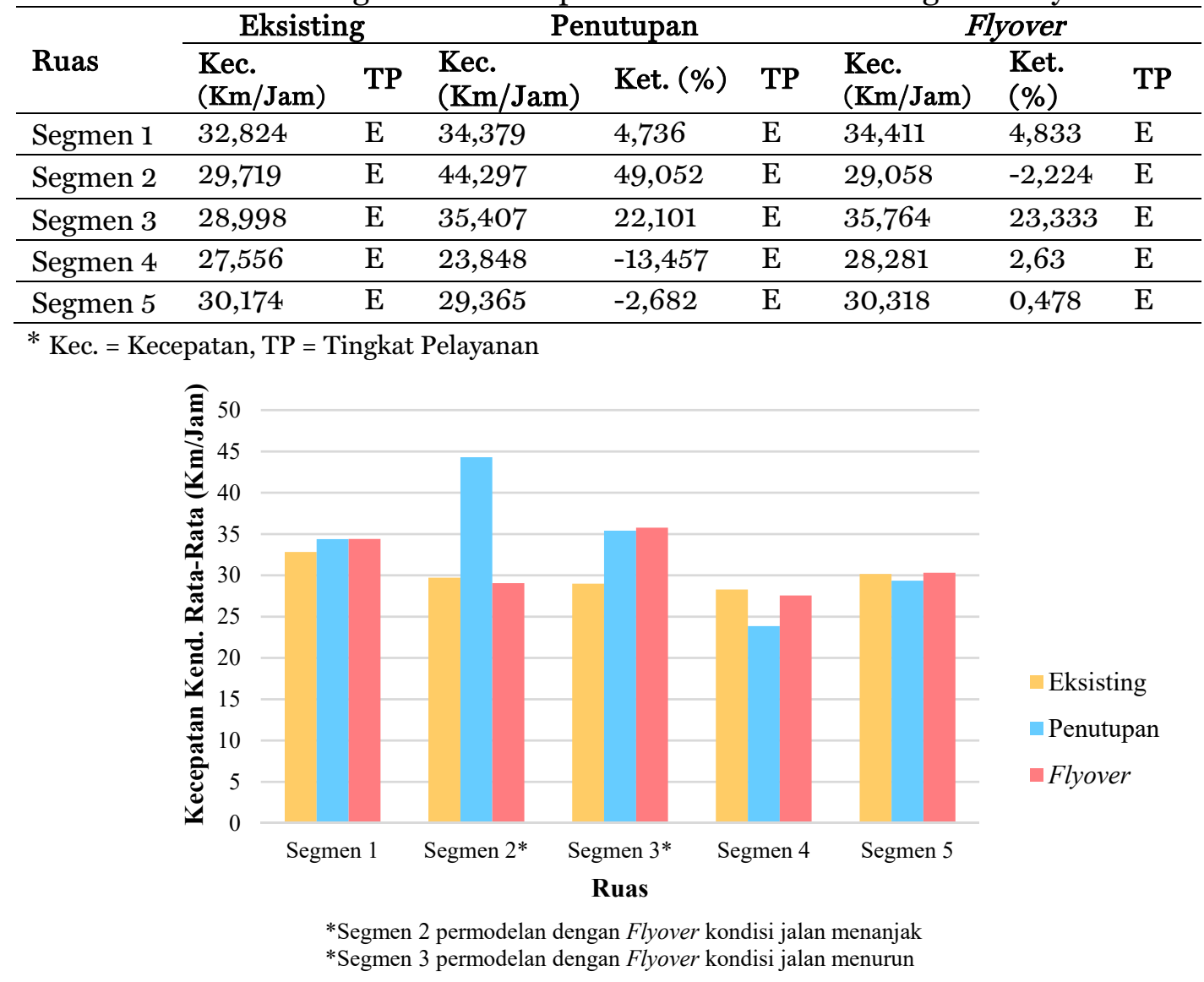

Gambar 5. Grafik Perbandingan Nilai Kecepatan

Pada permodelan penutupan perlintasan didapatkan kenaikan kecepatan kendaraan ratarata yang berarti kenaikan kinerja sebesar $4,736 \%$ pada ruas segmen 1 . Pada ruas segmen 2 
dan segmen 3 mengalami kenaikan yang cukup signifikan yaitu sebesar 49,052\% dan $22,101 \%$ karena terjadi pengurangan volume kendaraan Sedangkan pada ruas segmen 5 mengalami penurunan kecepatan sebesar $0,478 \%$, dan ruas segmen 4 sebesar $13,457 \%$ karena adanya pembebanan volume kendaraan.

Pada permodelan penutupan perlintasan dengan flyover, ruas flyover digunakan sebagai pembanding kinerja ruas flyover segmen 2 dan segmen 3. Berdasarkan tabel di atas, didapatkan kenaikan kecepatan sebesar 4,833\% pada ruas Utara, 2,63\% pada ruas segmen 4, dan $0,478 \%$ pada ruas segmen 5 . Pada ruas flyover (segmen 3 ) mengalami kenaikan yang cukup signifikan yaitu sebesar $23,333 \%$ karena terjadi pengurangan volume kendaraan dari ruas bawah flyover (segmen 3). Sedangkan pada ruas flyover (segmen 2) mengalami penurunan kecepatan sebesar $2,224 \%$.

Tingkat pelayanan ruas jalan H.O.S. Cokroaminoto mempunyai krtieria E, yaitu arus mendekati tidak stabil dengan kecepatan sekurang-kurangnya $10 \mathrm{~km} / \mathrm{jam}$ pada jalan perkotaan.

\section{KESIMPULAN}

Pada kondisi penutupan perlintasan, nilai derajat kejenuhan dan kecepatan semua ruas mengalami penurunan yang berarti kenaikan kinerja, kecuali pada segmen 4 mengalami kenaikan derajat jenuh dari 0,769 menjadi 1,009 karena terjadi pembebanan volume kendaraan. Pada kondisi penutupan perlintasan dengan flyover derajat kejenuhan ruas flyover (segmen 3) mengalami penurunan dari 0,35 menjadi 0,34 karena belum ada penambahan kendaraan dari bawah flyover area Selatan perlintasan. Segmen 4 juga mengalami penurunan dari 0,769 menjadi 0,457 karena telah terjadi pelebaran jalan. Ruas flyover (segmen 2) mengalami kenaikan nilai derajat kejenuhan dari 0,308 menjadi 0,311 karena telah terjadi penambahan kendaraan dari bawah flyover area Utara perlintasan. Sedangkan ruas segmen 1 dan segmen 5 tidak mengalami perubahan nilai derajat kejenuhan karena volume kendaraan yang melewati ruas tersebut sama dan tidak mengalami perubahan geometri. Kecepatan ruas segmen 1, flyover (segmen 3), segmen 4 dan segmen 5 mengalami kenaikan dari 32,824, 28,998, 27,556 dan 30,174 menjadi 34,411, 35,764, 28,281, dan 30,318, sedangkan kecepatan ruas flyover (segmen 2) mengalami penurunan dari 29,179 menjadi 29,058. Tingkat pelayanan ruas jalan H.O.S. Cokroaminoto mempunyai krtieria E pada ketiga kondisi, yaitu arus mendekati tidak stabil dengan kecepatan sekurangkurangnya $10 \mathrm{~km} / \mathrm{jam}$ pada jalan perkotaan.

\section{SARAN}

1. Jika perlintasan sebidang Jalan H.O.S. Cokroaminoto ditutup untuk keamanan lalu lintas, maka solusi terbaik adalah dengan membangun flyover namun dibutuhkan pelebaran jalan di Jalan Pembela Tanah Air dengan konsekuensi memakan ruang terbuka hijau (RTH) di jalan tersebut sehingga RTH perlu dipindah ke daerah lain.

2. Penelitian dapat dilanjutkan dan dikembangkan dengan mempertimbangkan adanya pengaruh hambatan samping pada area sekitar perlintasan sebidang kereta api Jalan H.O.S. Cokroaminoto misal dengan memperhitungkan parkir di badan jalan, dan adanya kendaraan yang keluar-masuk gang sekitar perlintasan tersebut sehingga dapat memberikan solusi atas kepadatan lalu lintas.

3. Melakukan survei volume lalu lintas tambahan pada ruas - ruas jalan yang menjadi rute penutupan perlintasan agar hasil analisis mendekati kondisi sebenarnya. 


\section{DAFTAR PUSTAKA}

AG, P. T. V. A. (2016). VISSIM 9.o-11 User Manual. Karlsruhe.

Direktorat Jenderal Bina Marga. (1997). Manual Kapasitas Jalan Indonesia (MKJI). Jakarta: Departemen Pekerjaan Umum.

Hartono. (2016). Perlintasan Sebidang Kereta Api di Kota Cirebon. Jurnal Penelitian Transportasi Darat, 18(1), 45-62.

Menteri Perhubungan Republik Indonesia. (2011). Peraturan Menteri Perhubungan Nomor 36 Tahun 2011 tentang Perpotongan dan/atau Persinggungan antara Jalur Kereta Api dengan Bangunan Lain Pasal 2, 3, 4, dan 7. Jakarta: Menteri Perhubungan.

Menteri Perhubungan Republik Indonesia. (2015). PM No.96 Tahun 2015 Tentang Pedoman Pelaksanaan Kegiatan Manajemen dan Rekayasa Lalulintas. Jakarta: Menteri Perhubungan.

Mulyono, Slamet, G., \& Suwardi. (2006). Analisis Lalulintas Pertemuan Jalan Raya dengan Lintasan Kereta Api Ledok Sari di Surakarta. Jurnal Eco Rekayasa, 2(1).

Muthmainnah, S. (2015). Pengaruh Tundaan dan Panjang Antrian terhadap Konsumsi Bahan Bakar Akibat Penutupan Pintu Perlintasan Kereta Api (Studi Kasus Perlintasan Kereta Api di Timur Stasiun Lempuyangan). Jurnal Universitas Islam Indonesia, 1-10.

Muttaqin, M. Z., Sumarsono, A., \& Dewi, H. (2014). Pengaruh Tundaan dan Antrean Panjang Kendaraan terhadap Konsumsi Bahan Bakar Minyak Aakibat Penutupan Pintu Perlintasan Kereta Api (Studi Kasus pada Perlintasan Kereta Api Purwosari, Surakarta). E-Jurnal Matriks Teknik Sipil, 344-350.

Purnama, D. P., \& Indarto, H. (2017). Desain Fly Over Sebidang Jalan Kereta Api Di Jalan Slamet Riyadi Surakarta. JURNAL TEKNIK SIPIL, 6(1), 275-281.

Putra, R. K., Mahmudah, N., \& Setiawan, D. (2013). Inspeksi Keselamatan di Perlintasan Sebidang pada JPL 348 KM 163 + 220, Jalan Sorowajan Baru, Yogyakarta. Jurnal Universitas Muhammadiyah Yogyakarta, 1-8.

Republik Indonesia. (2007). Undang - Undang Nomor 23 Tahun 2007 tentang Perkeretaapian Pasal 91 ayat 1 dan 2, Pasal 124. Jakarta: Sekertariat Negara.

Republik Indonesia. (2009). Peraturan Pemerintah Nomor 72 Tahun 2009 tentang Lalu Lintas dan Kereta Api Pasal 110. Jakarta: Sekretariat Negara.

Sitorus, F. P., \& Surbakti, M. S. (2013). Studi Pengaruh Perlintasan Sebidang Jalan dengan Rel Kereta Api Terhadap Karakteristik Lalu Lintas (Studi Kasus: Perlintasan Kereta Api Jalan Sisingamangaraja, Medan). Universitas Sumatera Utara, 2(2).

Tamin, O. (2000). Perencanaan dan Permodelan Transportasi. Bandung: Institut Teknologi Bandung.

Widodo, A. P. (2007). Kajian Penutupan Perlintasan Sebidang antara Jalan Kereta Api dengan Jalan Raya pada lokasi Jalan KH . Mas Mansyur dan Jalan Abdul Syafi'ie Provinsi Daerah Khusus Ibukota Jakarta. Article of Civil Engineering, Universitas Gunadarma, 1-40.

Winnetou, I. A., \& Munawar, A. (2015). Penggunaan Software VISSIM untuk Evaluasi Hitungan MKJI 1997 Kinerja Ruas Jalan Perkotaan.

Yusyadiputra, M., Hermawanto, R., Pudjianto, B., \& Yulipriyono, E. (2014). Pengaruh Penutupan Pintu Perlintasan Jalan Rel Terhadap Kinerja Lalu Lintas Jalan Raya Di Perlintasan Kaligawe Semarang Dan Kaliwungu Kendal. Jurnal Karya Teknik Sipil, 3, 723-735. 